\title{
PERKEMBANGAN PEMAHAMAN SISWA PADA MATERI OPERASI BILANGAN BULAT DALAM SETTING PEMBELAJARAN MATEMATIKA REALISTIK BERBANTUAN MEDIA "MOGER" DI KELAS IV
}

\author{
Ach. Jazuli \\ Universitas Negeri Surabaya \\ ach.jazuli4774@yahoo.com
}

\begin{abstract}
Abstrak
Penelitian ini bertujuan Mendeskripsikan Perkembangan Pemahaman Siswa pada Operasi Hitung Bilangan Bulat dalam setting Pembelajaran Matematika Realistik berbantuan media "Mobil Bergerak" di kelas IV. Penelitian ini deskriptif kualitatif dan kuantitatif, penelitian yang dilakukan dengan menjelaskan atau menggambarkan variabel masa lalu dan sekarang yang bertujuan untuk membuat deskripsi, gambaran atau lukisan secara sistematis, faktual dan akurat mengenai fakta-fakta serta hubungan antara fenomena yang diselidiki. Hasil dari Tes pertama, tes kedua, dan tes ketiga siswa mengalami peningkatan ditunjukkan dengan nilai tertinggi dari 45 ke 77,5 dan ke 100, Nilai terendah dari 10 ke 25 dan 45 , nilai rata-rata dari 19,17 ke 54,06 dan 74,90 . Tingkat pemahaman rata-rata kelas dari sangat rendah ke sedang dan tinggi.Hasil perbandingan dari tes pertama, tes kedua, dan tes ketiga menunjukkan perubahan yang lebih baik atau maju dengan begitu dapat disimpulkan siswa mengalami perkembangan pemahannya dalam operasi hitung bilangan bulat melalui setting pembelajaran matematika realistik berbantuan media "MOGER". Berdasarkan hasil data, dapat disimpulkan siswa mengalami perkembangan pemahaman dalam operasi hitung bilangan bulat dengan menggunakan setting pembelajaran matematika realistik berbantuan media "MOGER" di kelas IV.
\end{abstract}

Kata Kunci: Pemahaman Siswa Pada Operasi Bilangan Bulat, Pembelajaran Matematika Realistik, Media "MOGER".

Abstract

This study aims to describe the development of understanding of students on Operation Count Integer in setting medium-aided Realistic Mathematics Education "Moving Cars" in the fourth grade. This research is descriptive qualitative and quantitative research conducted to explain or illustrate the past and present variables which aims to create a description, picture or painting in a systematic, factual and accurate information on the facts and the relationship between the phenomenon investigated. Results of the first test, a second test and third test 
students have shown improvement with the highest score of 45 to 77.5 and to 100 , the lowest value of 10 to 25 and 45, the average value of 19.17 to 54.06 and 74.90 . Level of understanding of the average grade from very low to medium and high. The comparison of the first test, a second test and third test showed changes for the better or forward so we can conclude pemahannya students progressing in integer arithmetic operations by setting realistic mathematics-assisted learning media "Moger". Based on the results of the data, it can be concluded the students to experience growth in the understanding of integer arithmetic operations using mathematical learning setting realistic media-assisted "Moger" in the fourth grade

Keywords: Students Understanding On Operations Integer, Realistic Mathematics Education, Media "Moger".

\section{PENDAHULUAN}

Keengganan guru dalam mencipta dan menggunakan media pembelajaran mengakibatkan peran sumber belajar semakin kecil, sedang media pembelajaran yang tersedia tidak dimanfaatkan. Walaupun digunakan, cara penyajiannya tidak melalaui proses perencanaan dan pembuatan yang baik dan benar ditinjau dari segi teori pembuatan, pemilihan peng-gunaan sumber belajar (Sadiman, Arief S., 1993).

Tugas utama guru adalah mengajar. Setiap akan mengajar seorang guru harus mempersiapkan berbagai macam cara agar materi pelajaran yang disampaikan kepada peserta didik dapat diterima serta dipahami dengan mudah. Selama ini masih banyak guru yang me-laksanakan pembelajaran dengan cara-cara konvensional disaat me-nyampaikan materi pelajaran, pem-belajaran didominasi oleh guru, kreativitas siswa tidak diperhatikan.

Kebanyakan siswa mengalami kesulitan dalam mengaplikasikan matematika ke dalam situasi kehidupan real. Guru dalam pembelajarannya di kelas tidak mengaitkan dengan skema yang telah dimiliki oleh siswa dan siswa kurang diberikan kesempatan untuk me-nemukan kembali dan meng-konstruksi sendiri ide-ide matematika.

Proses berpikir anak-anak mulai dari hal-hal yang sederhana sampai kepada hal-hal yang rumit khususnya untuk peserta didik Sekolah Dasar. Namun, Siswa SD tahap perkembangannya adalah operasional konkrit berpikirnya didasarkan pada objek-objek nyata. Sesuai dengan teori perkembangan intelektual (Aisyah, 2007), berpendapat bahwa proses berpikir manusia merupakan suatu per-kembangan yang bertahap dari berpikir intelektual konkrit keabstrak melalui empat tahap perkembangan yaitu periode sensori motor (0-2 tahun), periode pra-operasional (2-7 tahun), periode operasional konkrit (7-12 tahun), periode operasional formal ( $>12$ tahun).

Kenyataannya matematika sering kali dianggap pelajaran yang menakutkan dan kurang disenangi siswa. Rasa takut terhadap pelajaran matematika (fobia matematika) 
sering kali menghinggapi perasaan para siswa dari tingkat SD sampai dengan SMA bahkan hingga perguruan tinggi. Hal ini pemahaman materi perlu diperhatikan mulai dari awal anak mengenal pelajaran matematika dan materi pelajaran matematika yang pertama dikenalkan pada siswa yaitu materi penjumlahan dan pengurangan karena penjumlahan merupakan modal awal siswa sebelum mempelajari jenis operasi hitung yang lain.

Khusus bagi siswa sekolah dasar yang taraf berpikirnya masih sangat sederhana, untuk dapat menanamkan pemahaman terhadap materi secara baik perlu adanya dukungan benda-benda konkrit atau model. Misalnya dalam mengajar pokok bahasan "Operasi Penjumlahan dan Pengurangan Bilangan Bulat" pada kelas IV Sekolah Dasar, diperlukan dukungan alat bantu dan pembelajaran yang relevan dengan materi yang akan disampaikan, sehingga dapat mempermudah dan memperjelas pemahaman siswa terhadap materi yang diajarkan. Media pembelajaran dibuat untuk memfasilitasi tercapainya pemahaman siswa tersebut. Pemahaman materi tersebut sulit dicapai jika guru masih mengandalkan ucapan dirinya seperti mereka diajar oleh gurunya pada waktu sekolah zaman dulu.

Kehadiran media pembelajaran yang mampu meningkatkan kualitas mutu pelajaran. Salah satu gambaran yang paling banyak dijadikan acuan sebagai landasan teori penggunaan media dalam proses belajar adalah Dale's Cone of Experiences (Kerucut Pengalaman Dale). Dalam usaha memanfaatkan media pada proses pembelajaran, Edgar dale mengadakan klasifikasi pengalaman menurut tingkatan dari yang paling konkrit ke yang paling abstrak (Munadi, 2008).

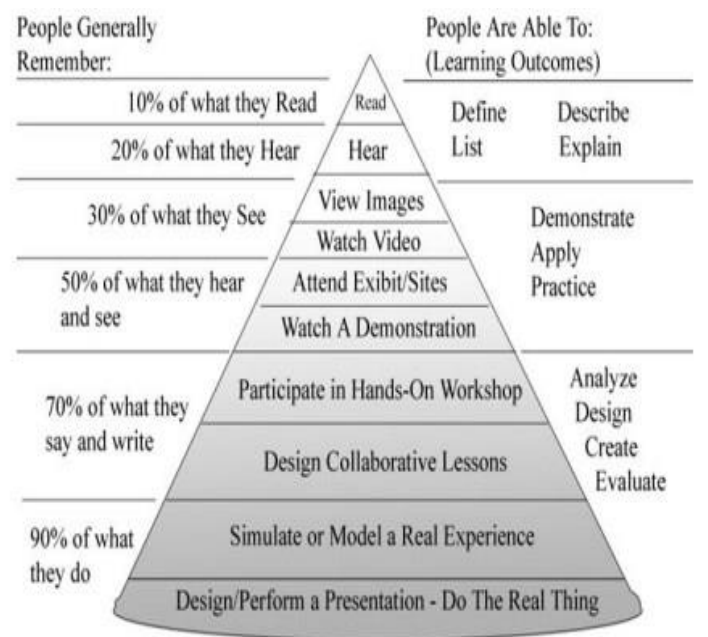

Berdasarkan kerucut pengalaman Dale di atas, media pembelajaran yang paling berpengaruh adalah pembuatan simulasi atau model pengalaman nyata dan melakukan dengan benda nyata (simulate or model real experience dan do the real thing), disebutkan pada tahap tersebut pembelajaran mencapai tingkat pe-mahaman yang paling tinggi dimana siswa dibawa untuk melakukan pengalaman nyata melalui media pembelajran. Ada satu 
hal yang menarik untuk diamati, yaitu ekstraksi konsep yang tepat dari situasi yang konkrit, Ahlfors me-negaskan pentingnya penggunaan situasi konkrit dalam pembelajaran (Wijaya, 2012). Berdasarkan pengalaman Dale pemahaman siswa dapat dikembang-kan melalui media yang berdasarkan pada kehidupan yang realistik (nyata).

Media pembelajaran dapat menggunakan alat peraga seperti media "Mobil Bergerak" dapat mempermudah peserta didik dalam menyelesaikan soal operasi hitung bilangan bulat. Menurut, satu hal yang perlu mendapat perhatian adalah teknik penggunaan alat peraga dalam pembelajaran matematika secara tepat. Pemanfaatan media/alat peraga yang dilakukan secara benar akan memberikan kemudahan bagi peserta didik untuk membangun sendiri pengetahuan yang sedang dipelajarinya. "Mobil Bergerak" adalah suatu media yang diadopsi dari pita garis bilangan. Media ini lebih cenderung merupakan alat permainan matematika, dan pada umumnya digunakan untuk me-ngenalkan atau melakukan operasi hitung dasar pada sistem bilangan bulat. Media Mobil Bergerak alat bantu yang terbuat dari karton yang digambar rute/sirkuit jalan yang melingkar tanpa beraturan dimana rute tersebut terdapat angka bilangan positif dengan warna hijau disisi sebelah kanan dan sebelah kirinya terdapat angka bilangan negatif dengan warna kuning yang memiliki skala yang sama disetiap angka bilangannya. Penggunaan media ini membutuhkan alat pemeraga (model) berupa mobil-mobilan yang kecil yang dijalankan oleh siswa (siswa menggerakkan kekanan atau kekiri, maju atau mundur dan setiap gerakannya mengandung makna atau mewakili bilangan-bilangan yang dioperasikan). Selain media, proses pembelajaran juga harus didukung dengan pembelajaran yang sesuai. Menurut (Suryanto, 2010), PMR merupakan suatu inovasi pendidikan matematika atau inovasi pembelajar-an matematika yang sejalan dengan teori konstruktivisme. Salah satu sebab mengapa PMR diterima dibanyak Negara adalah karena konsep PMR itu sendiri. Berdasarkan pemikiran Hans Freudenthal, dalam PMR matematika dianggap sebagai aktivitas insan (mathematics as human activitics) dan harus matematika dikaitkan dengan realitas.

Menurut filsafat PMR siswa harus diberi kesempatan untuk menemukan kembali (to reinvent) matematika di bawah bimbingan orang dewasa, dan penemuan kembali ide konsep matematika tersebut harus dimulai dari penjajahan berbagai persoalan dan situasi dunia nyata. Dalam PMR, matematika tidak dipandang sebagai ilmu atau bidang kajian yang sudah jadi, tetapi dipandang sebagai sesuatu yang harus dikonstruksi sendiri oleh anak didik. Anak didik adalah pihak yang aktif mengkonstruksi konsep-konsep matematika, fungsi guru tidak lagi terutama sebagai pengajar, tetapi lebih dipandang sebagai pendamping atau fasilitator bagi anak didik.PMR menempatkan realitas dan lingkungan anak didik sebagai titik awal pembelajar. Pembelajaran tidak dimulai dari definisi, teorema, atau sifat-sifat dan selanjutnya diikuti dengan contoh-contoh, namun sifat, definisi, teorema itu diharapkan ditemukan sendiri oleh anak didik. Dengan demikian jelas bahwa dalam pembelajaran matematika realistik anak didik didorong atau ditantang 
untuk aktif bekerja bahkan diharapkan dapat mengkonstruksi atau membangun sendiri pengetahuan yang akan diperoleh (Hobri., 2009).

Kelebihan PMR di atas dapat memberikan inspirasi untuk me-ngembangkan pemahaman siswa menggunakan PMR, memasukkan media pembelajaran yang digunakan dengan keadaan nyata dalam kehidupan sehari-hari supaya matematika lebih menarik dan tidak terlalu abstrak, dapat dilakukan dengan Pembelajaran Matematika Realistik berbantuan media "Mobil Bergerak (MOGER)". Banyak per-soalan yang muncul pada sistem bilangan bulat di sekolah dasar, misalkan pada waktu mereka akan melakukan operasi hitung seperti: $4+(-7)$; $(-6)+9 ;(-3)-(-6)$; dan sebagainya. (Muhsetyo, 2009:3.10). Kesulitan dalam memahami masalah tersebut tidak pahamnya siswa membedakan antara operasi hitung (penjumlahan, pengurangan, per-kalian, pembagian) dan bilangan bulat (positif, nol, dan negatif). Berdasar-kan pengalaman penulis, masih banyak siswa yang mengalami kesulitan dalam memahami materi operasi hitung bilangan bulat, hal ini dapat dilihat dari kesalahan siswa dalam mengerjakan soal seperti $4-(-2)=2$ dan $(-7)-3=4$.

Menggunakan Pembelajaran Matematika Realistik berbantuan media "Mobil Bergerak" diharapkan dapat menyajikan pembelajaran yang sesuai dan cocok dengan proses berpikir siswa sehingga siswa dapat mengembangkan pemahamannya terhadap operasi hitung bilangan bulat.

Harapan selanjutnya adalah siswa tidak lagi merasa takut dan bosan serta malas, melainkan menyenangi serta meningkatkan minat dan selera belajar mereka terhadap belajar matematika. Matematika tidak lagi menjadi pelajaran sulit, tetapi siswa merasa mudah dalam mempelajari matematika. Jika semua itu terwujud, memungkinkan pemahaman belajar siswa terhadap mata pelajaran matematika akan semakin berkembang. Berdasarkan uraian di atas penulis tertarik melaksanakan penelitian dengan judul "Perkembangan Pemahaman Siswa Pada Materi Operasi Bilangan Bulat Dalam Setting Pembelajaran Matematika Realistik Berbantuan Media 'Moger' Di Kelas IV”

\section{METODE PENELITIAN}

Penelitian ini adalah penelitian deskriptif kualitatif dan kuantitatif. Menurut Sugiyono "metode penelitian deskriptif adalah metode penelitian yang dilakukan untuk mengetahui nilai variabel mandiri atau lebih (independen) tanpa membuat perbandingan atau menggabungkan antara variabel satu dengan yang lain) (Sugiono, 2014). Penelitian kualitatif adalah penelitian yang difokuskan pada satu fenomena saja yang dipilih dan ingin dipahami secara mendalam, dengan mengabaikan fenomena-fenomena lainnya. Penelitian kuantitatif adalah penelitian yang berbentuk angka atau data kualitatif yang diangkakan/scoring. 
Áth. Lazufi

Perkembangan pemahaman siswa dalam setting matematila realistil berbantuan Media MOGER

\section{HASIL PENELITIAN DAN PEMBAHASAN}

Masalah bagi siswa terutama kesulitan dalam memahami masalah yang berkaitan dengan operasi hitung pada bilangan bulat. Masalah tersebut mendorong peneliti untuk mengatasinya dengan menerapkan setting pembelajaran matematika realistik berbantuan media "MOGER" pada materi operasi hitung bilangan bulat. Berikut adalah perolehan siswa dalam pemahaman operasi hitung bilangan dari Tes pertama, tes kedua, dan tes ketiga.

Tabel 1. Data Hasil Perolehan Tes pertama,Tes kedua, dan Tes ketiga

\begin{tabular}{|l|l|l|l|l|}
\hline $\begin{array}{l}\text { N } \\
\text { o. }\end{array}$ & Pencapaian & $\begin{array}{l}\text { Tes } \\
\text { I }\end{array}$ & $\begin{array}{l}\text { Tes } \\
\text { II }\end{array}$ & $\begin{array}{l}\text { Tes } \\
\text { III }\end{array}$ \\
\hline 1 & $\begin{array}{l}\text { Nilai Rata- } \\
\text { rata }\end{array}$ & $\begin{array}{l}19,1 \\
7\end{array}$ & $\begin{array}{l}54,0 \\
6\end{array}$ & $\begin{array}{l}74,9 \\
0\end{array}$ \\
\hline 2 & $\begin{array}{l}\text { Nilai } \\
\text { tertinggi }\end{array}$ & 45 & 77,5 & 100 \\
\hline 3 & $\begin{array}{l}\text { Nilai } \\
\text { terendah }\end{array}$ & 10 & 25 & 45 \\
\hline 4 & $\begin{array}{l}\text { SSiswa } \\
\text { Berpemaha } \\
\text { nan ST }\end{array}$ & 0 & 0 & 10 \\
\hline 5 & $\begin{array}{l}\text { SSiswa } \\
\text { Berpemaha } \\
\text { nan T }\end{array}$ & 0 & 10 & 6 \\
\hline 6 & $\begin{array}{l}\text { ESiswa } \\
\text { Berpemaha } \\
\text { nan S }\end{array}$ & 1 & 6 & 8 \\
\hline 7 & $\begin{array}{l}\text { ESiswa } \\
\text { Berpemaha } \\
\text { nan R }\end{array}$ & 8 & 8 & 0 \\
\hline 8 & $\begin{array}{l}\text { ESiswa } \\
\text { Berpemaha } \\
\text { nan SR }\end{array}$ & 15 & 0 & 0 \\
\hline 9 & $\begin{array}{l}\text { Tingkat } \\
\text { Pemahaman } \\
\text { Rata-rata } \\
\text { Kelas }\end{array}$ & SR & $\mathrm{S}$ \\
\hline
\end{tabular}


Berdasarkan tabel di atas siswa adanya perubahan yang lebih baik dari pencapaian siswa pada tes pertama, kedua, dan ketiga terhadap operasi bilangan bulat dilihat dari nilai rata-rata, nilai tertinggi, nilai terendah Tes pertama, tes kedua, dan tes ketiga menunjukan bahwa Nilai tertinggi dari 45 ke 77,5 dan ke 100, Nilai terendah dari 10 ke 25 dan 45, nilai rata-rata dari 19,17 ke 54,06 dan 74,90. Perkembangan pemahaman siswa terlihat dalam Tes pertama ada 15 siswa yang berpemahaman sangat rendah menjadi tidak ada siswa yang berpemahaman rendah dalam tes kedua dan ketiga, tes pertama ada 8 siswa berpemahaman rendah dalam tes kedua masih sama ada 8 siswa yang berpehaman rendah tetapi dites ketiga tidak ada yang berpemahan rendah, tes pertama 1 siswa berpemahaman sedang dalam tes kedua menjadi 6 siswa dan 8 siswa dalam tes ketiga, dan tidak ada siswa yang berpemahaman tinggi dan berpehaman sangat tinggi dalam tes pertama tetapi dalam tes kedua 10 siswa berpehaman tinggi dan tidak ada yang berpemahaman sangat tinggi tetapi dalam tes ketiga siswa ada 6 siswa yang berpemahaman tinggi dan 10 siswa yang berpemahaman sangat tinggi. Tingkat pemahaman rata-rata kelas dari sangat rendah ke sedang dan tinggi.Hasil perbandingan dari tes pertama, tes kedua, dan tes ketiga menunjukkan perubahan yang lebih baik atau maju dengan begitu siswa mengalamiperkembangan pemahan-nya dalam operasi hitung bilangan bulat melalui setting pembelajaran matematika realistik berbantuan media "MOGER".Membandingkan keadaan dalam dua periode waktu yang berbeda dapat menafsirkan bagaimana kemajuan perkembangan yang dicapai, misalkan dengan melalui evaluasi (Nurkancana, 1986).

Hasil tes pertama, kedua, dan ketiga nilai siswa mengalami perubahan yang lebih baik dari hasil itu dapat disimpulkan pemahaman siswa pada materi operasi hitung bilangan bulat mengalami perkem-bangan. Siswa dikatakan mengalami perkembangan pemaha-mannya jika tes pertama ketes kedua mengalami perkembangan, tes kedua ketes ketiga mengalami perkembangan atau jika tes pertama ketes kedua tidak mengalami perkembangan tetapi tes kedua ketes ketiga mengalami perkembangan maka siswa dikatakan mengalami perkem-bangan pemaha-mannya, sebaliknya jika tes pertama ketes kedua tidak mengalami perkembangan, tes kedua ketes ketiga tidak mengalami perkembangan atau tes pertama ketes kedua mengalami perkembangan tetapi dites kedua ketes ketiga tidak mengalami perkembangan. Tabel di atas menunjukkan seluruh siswa mengalami perubahan yang lebih baik dari tes pertama ketes kedua dan tes kedua ketes ketiga, maka seluruh siswa mengalami perkembangan pemaha-mannya terhadap operasi hitung bilangan bulat.

\section{KESIMPULAN}

Berdasarkan hasil penelitian perkembangan pemahaman siswa terhadap operasi hitung bilangan bulat dalam setting pembelajaran Matematika Realistik berbantuan media 
Tach. Lazufi

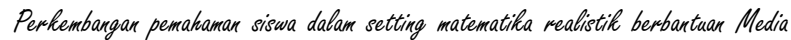
MOGER

"MOGER" pada siswa kelas IV SDN Ambunten Timur II, dapat diperoleh data sebagai berikut.

Hasil dari Tes pertama, tes kedua, dan tes ketiga menunjukan bahwa Nilai tertinggi dari 45 ke 77,5 dan ke 100, Nilai terendah dari 10 ke 25 dan 45, nilai rata-rata dari 19,17 ke 54,06 dan 74,90. Tingkat pemahaman rata-rata kelas dari sangat rendah ke sedang dan tinggi. Hasil perbandingan dari tes pertama, tes kedua, dan tes ketiga menunjukkan perubahan yang lebih baik atau maju dengan begitu siswa mengalami perkembangan pemahannya dalam operasi hitung bilangan bulat melalui setting pembelajaran matematika realistik berbantuan media "MOGER"

Hasil penelitian dari tes pertama, kedua, ketiga mengalami perubahan yang lebih baik sehingga dapat disimpulkan perkembangan pemaha-man siswa pada operasi bilangan bulat mengalami perkembangan.

Siswa mengalami perkembangan pemahaman pada materi operasi bilangan bulat dapat dilihat juga dari pemahaman awal siswa terhadap garis bilangan bahwa ujung anak panah merupakan hasil dari operasi bilangan bulat berkembang pemahamannya bahwa hasil dari operasi bilangan bulat tidak hanya ditentukan oleh anak panah bisa juga ada dipangkal anah panah.

\section{DAFTAR PUSTAKA}

Aisyah, N. (2007). Pengemban-gan Pembelajaran Matematika SD. Dirjen Dikti Depdiknas.

Hobri. (2009). Model-Model Pembelajaran Inovatif. CSS.

Munadi, Y. (2008). Media pembelajaran Sebuah Pembe-lajaran Baru. Gaung Persada. Nurkancana, W. dan S. (1986). Evaluasi Pendidikan. Usaha Nasional.

Sadiman, Arief S., dkk. (1993). Media Pendidikan: Pengertian, Pengem-bangan, dan Pemanfaatannya. PT Grapindo Persada.

Sugiono. (2014). Metode Penelitian Kuantitatif, Kualitatif, dan $R \&$ D. Alfabeta. Suryanto, dkk. (2010). Pendidikan Matematikarealitik Indonesia (PMRI. IPPMRI. Wijaya, A. (2012). Pendidikan Matematika Realistik Suatu Altematif Pembelajaran Pembela-jaranMatematika. Graha Ilmu. 